\title{
Comparison Among Aerobic Exercise and Other Types of Interventions to Treat Depression: A Systematic Review
}

Antonio Marcos de Souza Moura, Murilo Khede Lamego, Flávia Paes, Nuno Barbosa Ferreira Rocha, Vitor Simões-Silva, Susana Almeida Rocha, Alberto Souza de Sá Filho, Ridson Rimes, João Manochio, Henning Budde, Mirko Wegner, Gioia Mura, Oscar Arias-Carrión, Ti-Fei Yuan, Antonio Egidio Nardi and Sergio Machado

\begin{abstract}
Depression is a common and disabling disease that affects over 100 million people worldwide and can have a significant impact on physical and mental health, reducing their quality of life. Thus, the aim of this article was to provide information on research results and key chains related to the therapeutic effects of chronic aerobic exercise compared with other types of interventions to treat depression, which may become a useful clinical application in a near future. Researches have shown the effectiveness of alternative treatments, such as physical exercise, minimizing high financial costs and minimizing side effects. In this review, the data analyzed allows us to claim that alternative therapies, such as exercise, are effective on controlling and reducing symptoms. $69.3 \%$ of the studies that investigated the antidepressant effects of exercise on depressive were significant, and the other $30.7 \%$ of the studies improved only in general physiological aspects, such as increased oxygen uptake, increased use of blood glucose and decreased body fat percentage, with no improvement on symptoms of depression. From the sample analyzed, $71.4 \%$ was composed of women, and regarding the severity of symptoms, $85 \%$ had mild to moderate depression and only $15 \%$ had moderate to severe depression. However, there is still disagreement regarding the effect of exercise compared to the use of antidepressants in symptomatology and cognitive function in depression, this suggests that there is no consensus on the correct intensity of aerobic exercise as to achieve the best dose-response, with intensities high to moderate or moderate to mild.
\end{abstract}

Keywords: Aerobic exercise, cognitive functions, depression, randomized controlled trials.

\section{INTRODUCTION}

Depression is a common and disabling disease that affects over 100 million people worldwide, and may have a significant impact on the people's physical health, as well as reduce their quality of life [1]. In addition, depression is associated with impairments in cognitive skills. [2] Are usually treated with antidepressants and psychological treatments, alternative therapies such as exercise are also used [3]. Studies have shown that aerobic exercise is related in improving cognitive function [4]. It is well described in the literature that the exercise can provide major health benefits, such as: improved physical conditioning; decreased bone and muscular loss; increased strength; coordination and balance; reduced the functional incapacity, the intensity of the negative thoughts and physical diseases and improved the wellbeing and mood [5]. Studies suggest that regular exercise can improve various physiological and psychological factors in depressed patients [6]. The exercise has been used as an important adjunctive to the treatment of depression, being recommended by the fact that stimulates the secretion of hormones that increase the feeling of pleasure and well-being: like the release of monoamines, serotonin, dopamine and norepinephrine [7]. Production levels of neurotrophic factor (BDNF) derived from brain also have an intimate relationship with 
exercise, where hippocampal neurogenesis and increased expression of neurotrophic factor have been observed in individuals who do exercise $[8,9]$. Some studies have shown that combined treatment of antidepressants and regular exercise is a good strategy for the reduction of symptoms $[10,11]$. However, these responses can be directly influenced by several factors such as: the patient's response to treatment, type of drug used, volume and intensity of exercise [11]. In this regard, Stanton and Reaburn suggests that aerobic exercise supervised 3-4 days a week, with moderate intensity for at least 9 weeks appear to be effective in the treatment of depression [12]. It is known that the effect of exercise on long term appears to be more effective as compared to the benefits of exercise in the short term. Nevertheless, one study showed that aerobic interval training intensity of $80 \%$ of maximum heart rate (MHR) in a short period of training (i.e., 10 days) could substantially reduce the severity of symptoms of depression [13]. In relation to the long-term aerobic exercise, Blumenthal and colleagues demonstrated among its major findings that aerobic exercise with intensity between 70 and $85 \%$ of MHR with 30-minute sessions three times a week for four months showed similar effects of the antidepressants in relation to the reduction of symptoms [14]. However, there are still differences with regard to the exercise effect compared to the use of antidepressants on depression symptom. This is due to the fact that there is still no consensus on the correct intensity aerobic exercise so as to achieve the best dose-response, with high intensities to moderate or moderate to light [3]. In the same context, according to Cooney and colleagues, the effect size of exercise on depression may be moderated, but not due to very strict controls in studies, this effect can be reduced, making it impossible to say which the best type and intensity of exercise is actually more effective [1]. In this regard, Dunn and colleagues conducted a survey in attempt to study the dose-response to the exercise, using the amount recommended by the Public Health Recommendations for Physical Activity and verify that the results were effective in reducing symptoms. In this study, aerobic exercise was measured by energy expenditure, and ranked high for $17.5 \mathrm{kcal} / \mathrm{kg} /$ week and down to $7.0 \mathrm{kcal} / \mathrm{kg} /$ week for 12 weeks in 3 to 5 days/week, concluding that the group of high-spending energy in 3 to 5 days/week, was significant in reducing symptoms and remission rate of patients with severe to moderate levels of depression and that these results can be comparable with the rates reported in cognitive-behavioral therapy (CBT) and antidepressant studies [15].

The use of the energy expenditure required to quantify the dose of exercise to optimize the benefits related to health is well-accepted, however unusual due to its complexity and high cost. It is necessary; therefore, studies that use a way to quantify the dose-response to exercise at runtime and intensity of it, where we will have a better practical applicability, so most practitioners can actually train within the recommended target zone. Thus, this review paper aims to provide information on the current research and main findings related to the potential therapeutic effects of aerobic exercise compared to other types of interventions to treat depression that can become viable as clinical applications in the coming years.

\section{MATERIALS AND METHODS}

\section{Eligibility Criteria}

The structuring of the methods of the present study followed the proposals of PRISMA (Preferred Reporting Items for Systematic reviews and Meta-Analyses) [16]. Thus, PICOS 
("population", "intervention", "compared to control groups", "outcomes" and "study design") [16] approach will be adopted for the determination of eligibility.

1. Population - young adults, men and/or women, physically active or not, with a diagnosis of depression, aged between 18 and 60 years;

2. Intervention - patients must perform any type of aerobic exercise;

3. Comparators - aerobic exercise compared to antidepressants, others types of exercise, psychotherapy, psychoeducation, alternative therapy;

4. Outcomes - Symptoms and cognitive functions will be analyzed by scales/inventories of subjective symptoms of depression and neuropsychological tests.

5. Study Design - randomized clinical trials that assessed the chronic effect of aerobic exercise on depression;

\section{Sources of Information}

For gathering of studies the electronic databases MEDLINE / PubMed, ISI Web of Knowledge and SciELO were accessed. Experts on the subject of the present study were also contacted to send articles. To find additional articles, all tables were examined for evidence of previous systematic reviews and searched the references of randomized and controlled clinical trials when required. Furthermore, also references of all selected articles were analyzed. The search was closed on the day 20 June 2014.

\section{Search}

In all databases were made the combinations of the terms: aerobic exercise AND depression, aerobic exercise AND non-aerobic exercise with depression, aerobic exercise AND antidepressant, aerobic exercise AND psychotherapy, aerobic exercise AND psychoeducation.

\section{Selection of Studies}

The selection of the studies was carried out by two independent assessors, which in case of divergences have sought a consensus on the selection. The evaluation consisted in the filtering of the studies, starting with the analysis of the title, followed by the analyses of the abstract and after the analysis of the full article. In need to solve possible disagreements between the two evaluators, one third evaluator was requested for the due order. Complete relevant articles were obtained and evaluated with inclusion and exclusion criteria, described below.

\section{Data Collection}

The following data were extracted from the articles: sample size, participant characteristics, types of exercise, setting of the exercises (intensity, duration of exercise and total length), scales/inventories used, and main significant results. In addition several others information about the methods and outcomes were collected. These procedures done by two independent investigators, who reached a consensus, were performed in case of divergence.

\section{Exclusion Criteria}


Were excluded Articles that had no effective exercise intervention; those used otherwise associated with physical exercise that could create a risk of bias in the study, composite samples of the elderly, children and adolescents intervention; individuals with neurological disease; those who did not have detailed statistical procedure applied; studies assessing only the experimental group without a control group or did not show the results of varying symptomatology and cognitive functions.

\section{Risk of Bias in Studies}

For assessing the risk of bias of each article included, were analyzed: the presence of the eligibility criteria for participants in the sample; randomization of participants, the results of every moment from the analysis of more than $85 \%$ of the sample, the presence of the control group, and presentation of results and intergroup variability of results.

\section{RESULTS}

Based on the defined criteria, a total of 223 articles were found in the search conducted in the literature. Of these, 17 articles were duplicates and were therefore excluded, totalizing 206 articles. After the screening, 193 articles were excluded, which were not related to the proposed theme. 13 articles remained, and after new screening, any articles were excluded (see Fig. 1). Thus, studies were selected which properly met the criteria for this review. We found 13 studies about depression (Table 1). From the sample analyzed, 28.6\% was composed of men and $71.4 \%$ of women. With regard to the severity of symptoms, $85 \%$ had mild to moderate depression and only $15 \%$ had moderate to severe depression.

Assessment of risk of bias revealed that all articles selected met just one criteria. The majority of the articles have not results from $85 \%$ of sample (Table 2 ).

\section{DISCUSSION}

For better clarity and understanding, the discussion was addressed in subdivisions, that is, by subtopics.

\section{Exercise Plus Antidepressants Versus Antidepressants}

Blumental and colleagues [17] conducted a study with depressed patients who had disorders of moderate to severe intensity. In this study the effect of treatment of 16 weeks was compared in the following conditions: the group that used the antidepressant Sertraline, the exercise group and the group that combined the two treatment modalities. Aerobic exercise was performed on a treadmill with 10 minutes of warming, 30 minutes of running with intensity between 70 and $85 \%$ of heart rate reserve (HRR) and 5 minutes back to calm. At the end of the study, as a result of aerobic capacity and exercise tolerance in the exercise, there was a significant difference for groups using exercise when compared to the group receiving only antidepressant. Emphasizing that the exercise group had only a slight improvement over the group that combined the two methods, but without significant difference. Regarding the decreased scores of Hamilton Rating Scale for Depression (HAM-D) and Beck Depression Inventory (BDI), it was observed that the group receiving only antidepressant, responded 
quickly to treatment, whereas the group with mild depression compared to the group with severe depression responded more quickly to treatment when they realized the combination of antidepressant and exercise. They concluded that exercise can be considered as an antidepressant treatment for adults with depression, however, the antidepressant drug has a faster response than the initial therapeutic exercise; though exercise showed a similar effect to the drug after a period of 16 weeks. There was not consistent evidence to assert what were the physiological processes that could have influenced the improved mood associated with exercise, because both groups showed similar positive changes, possibly due to the short interval monitoring. Pilu and colleagues [10] performed a study aiming to confirm whether adjuvant exercise to the drug is able to improve the symptoms of depression in partial responders or non-responders to antidepressant treatment only for a period of 8 months. Were evaluated all females patients, group exercise plus antidepressant $\mathrm{N}=10$, and only antidepressant control group $\mathrm{N}=20$. Assessed at baseline and during eight months in the scales (HAM-D), Global Assessment Functioning (GAF) and Clinical Global Impression (CGI). The exercise consisted of two sessions with strength exercises for upper and lower limbs, with: 5 minutes for heating, 50 to strengthen and five minutes to calm back. The group of more antidepressant exercise significantly improved all scores during the 8 months of treatment compared to the control group. The authors concluded that the additional use of exercise was beneficial in the long term, reducing the symptoms of depression. However, long-term studies to randomized controlled large sample are needed to confirm the results, Blumental and colleagues [17] found similar results, but with aerobic exercise and short-term.

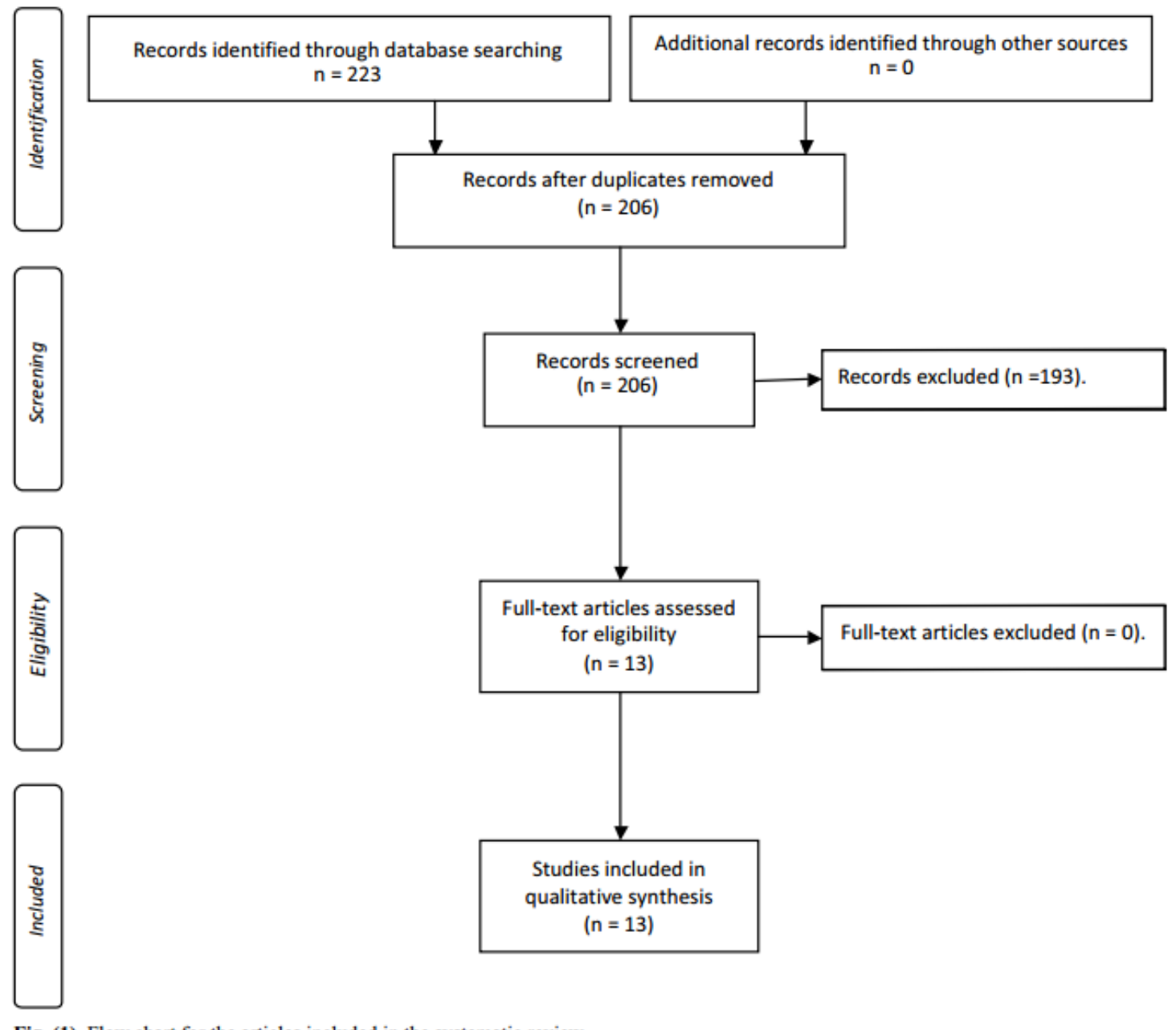

Fig. (1). Flow chart for the articles included in the systematic review. 
Mota-Pereira and colleagues [11] developed a research with 33 patients with major depressive disorder (MDD), both groups were selected: an exercise group and 22 patients with antidepressant and other antidepressant group with only 11 patients. The exercise consisted of 30-45minutes walk with moderate intensity 5 days / week for 12 weeks. To measure the symptoms of depression were used: HAMD17, BDI, CGI and GAF were measured at baseline, 4.8 and 12 weeks. The exercise group showed improvement in all operating parameters and depression, indicated by lower scores HAMD17, BDI and CGI and GAF scores higher in the 4.8 and 12 weeks compared to baseline and only after 12 weeks compared to the control group significantly. After the study, none of the members of the control group showed response to the treatment or remission, as in the exercise group, four showed response to treatment and five had remission, but not significant, these results may be related to the fact that these are severely depressed patients whose response or remission may take longer than the 12 weeks of this study because Blumental and colleagues [14] found significant rate of remission in patients with mild to moderate depression in 16 weeks. It was observed that moderateintensity aerobic exercise 30-45 minutes/day, 5 days/week for 12 weeks adjuvant pharmacologic therapy can be used as a strategy to improve symptoms of depression in refractory patients.

\section{Exercise Versus Antidepressants Versus Placebo}

Blumental and colleagues [14] conducted a study with patients with depressive disorders in low and moderate intensity over a period of 16 weeks of treatment, evaluated and compared four different groups, group supervised aerobic exercise, aerobic exercise at home, antidepressant 
Table 1. Papers that investigated the chronic effect of the exercise in patients with depression.

\begin{tabular}{|c|c|c|c|c|c|c|c|c|c|c|c|c|c|c|}
\hline 产 & 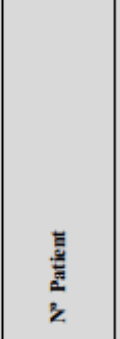 & $\begin{array}{l}\frac{3}{2} \\
\frac{3}{2} \\
\frac{3}{2} \\
\frac{3}{2}\end{array}$ & है & 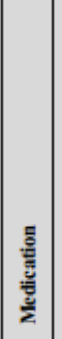 & $\frac{y}{c}$ & 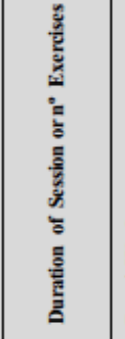 & $\begin{array}{l}\frac{y}{z} \\
\frac{z}{z} \\
z \\
z \\
z\end{array}$ & 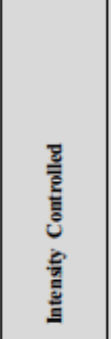 & 总 &  & 焉 & 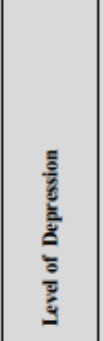 & 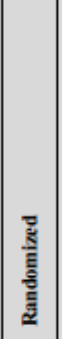 & है \\
\hline $\begin{array}{l}\text { Chalder } \\
\text { et al., } \\
{[23]}\end{array}$ & $\begin{array}{l}\mathrm{EG}=182 \\
\mathrm{CG}=179\end{array}$ & $\begin{array}{l}E G=40 \\
C G=38\end{array}$ & $\begin{array}{c}\text { Incentive } \\
\text { to } \\
\text { practice } \\
\text { exercises }\end{array}$ & No & 16 & $\begin{array}{c}150 \\
\text { minutes/ } \\
\text { per week }\end{array}$ & - & Yes & No & ICD-10 & BDI & $\begin{array}{c}\text { Mild to } \\
\text { moderate }\end{array}$ & Yes & $\begin{array}{l}\text { The intervention group } \\
\text { improved symptoms or } \\
\text { reduced the use of } \\
\text { antidepressants } \\
\text { compared to control. }\end{array}$ \\
\hline $\begin{array}{l}\text { Krogh et } \\
\text { al.., [21] }\end{array}$ & $\begin{array}{c}\mathrm{GAE}=56 \\
\mathrm{CG}=59\end{array}$ & $\begin{array}{c}\mathrm{GAE}=39 \\
\mathrm{CG}=43\end{array}$ & $\begin{array}{c}\text { Aerobic } \\
\text { and } \\
\text { stretching }\end{array}$ & No & 12 & 45 minutes & 3 & Yes & Yes & DSM-IV & $\begin{array}{c}\text { HAM-D } \\
\text { HAM-A } \\
\text { BDI }\end{array}$ & $\begin{array}{c}\text { Mild to } \\
\text { moderate }\end{array}$ & Yes & $\begin{array}{l}\text { Aerobic exercise did not } \\
\text { improve depressive } \\
\text { symptoms, improving } \\
\text { VO,max, but decreased } \\
\text { blood glucose }\end{array}$ \\
\hline $\begin{array}{c}\text { Mota- } \\
\text { Pereira et } \\
\text { al., [11] }\end{array}$ & $\begin{array}{l}E G=22 \\
C G=11\end{array}$ & $\begin{array}{l}\mathrm{EG}=48 \\
\mathrm{CG}=45\end{array}$ & Aerobic & Yes & 12 & $\begin{array}{l}30 \text { a } 45 \\
\text { minutes }\end{array}$ & 5 & Yes & No* & DSM-IV & $\begin{array}{l}\text { HAM-D, } \\
\text { BDI, } \\
\text { CGI e } \\
\text { GAF }\end{array}$ & $\begin{array}{c}\text { Moderate } \\
\text { to severe }\end{array}$ & Yes & $\begin{array}{c}\text { Exercise improved all } \\
\text { operating parameters } \\
\text { and depression, up to } 12 \\
\text { weeks compared to } \\
\text { baseline and after } 12 \\
\text { weeks compared to the } \\
\text { control group } \\
\text { significantly. }\end{array}$ \\
\hline \begin{tabular}{c|} 
Krogh et \\
al., [20]
\end{tabular} & $\begin{array}{c}\text { GREX }=55 \\
\text { GAE }=55 \\
\text { GRE }=55\end{array}$ & $\begin{array}{c}\text { GREX }=45 \\
\text { GAE }=43 \\
\text { GRE }=34\end{array}$ & $\begin{array}{l}\text { Acrobic, } \\
\text { strength } \\
\text { and } \\
\text { relaxation }\end{array}$ & No & 16 & \begin{tabular}{|c|}
90 minutes \\
6 exercises \\
2 a $3 x$ ( $8-$ \\
$12)$ reps.
\end{tabular} & 2 & $\begin{array}{c}\text { Yes } 75 \text { to } \\
89 \% \text { HRR } \\
50 \text { to } 75 \% \\
1 \text { RM }\end{array}$ & Yes & $\begin{array}{c}\text { DSM-IV } \\
\text { ICD-10 }\end{array}$ & BDI & $\begin{array}{c}\text { Mild to } \\
\text { moderate }\end{array}$ & Yes & $\begin{array}{l}\text { The exercise did not } \\
\text { improve depression, but } \\
\text { the strength group } \\
\text { improved work capacity } \\
\text { of patients. }\end{array}$ \\
\hline $\begin{array}{c}\text { Chu et } \\
\text { al., [19] }\end{array}$ & $\begin{array}{c}\mathrm{GAE}=36 \\
\mathrm{CG}=18\end{array}$ & $\begin{array}{c}\mathrm{GAE}=26 \\
\mathrm{CG}=24\end{array}$ & $\begin{array}{c}\text { Aerobic } \\
\text { and } \\
\text { stretching }\end{array}$ & No & 10 & $\begin{array}{c}30 \text { a } 40 \\
\text { minutes } \\
\text { EA } \\
30 \mathrm{~min} \\
\text { stretching }\end{array}$ & & $\begin{array}{c}\text { Yes } 40 \text { to } \\
55 \% \text { and } \\
65 \text { to } 75 \% \\
\mathrm{VO}_{2} \\
\text { reserve. }\end{array}$ & Yes & $\begin{array}{c}\text { ESE } \\
\text { DCSE }\end{array}$ & BDI-II & $\begin{array}{c}\text { Mild to } \\
\text { moderate }\end{array}$ & Yes & $\begin{array}{l}\text { The acrobic exercise of } \\
\text { low and high intensity } \\
\text { improved depression, } \\
\text { but significantly for the } \\
\text { high-intensity exercise. }\end{array}$ \\
\hline $\begin{array}{c}\text { Hoffiman } \\
\text { et al., } \\
{[18]}\end{array}$ & $\begin{array}{c}\mathrm{GEH}=53 \\
\mathrm{GSE}=51 \\
\mathrm{AG}=49 \\
\mathrm{PG}=49\end{array}$ & $\begin{array}{c}\mathrm{GEH}=52 \\
\mathrm{GSE}=51 \\
\mathrm{AG}=51 \\
\mathrm{PG}=51\end{array}$ & Acrobic & 盖 & 16 & - & 3 & $\begin{array}{c}\text { Yes, } 70 \text { to } \\
85 \% \text { HR } \\
\text { reserve }\end{array}$ & Yes & $\begin{array}{c}\text { DSM-IV } \\
\text { SCID }\end{array}$ & $\begin{array}{c}\text { BDI } \\
\text { HAM-D }\end{array}$ & $\begin{array}{c}\text { Mild to } \\
\text { moderate }\end{array}$ & Yes & $\begin{array}{c}\text { The exercise showed no } \\
\text { significant } \\
\text { improvements in } \\
\text { neurocognitive function } \\
\text { in depressed adults. }\end{array}$ \\
\hline $\begin{array}{c}\text { Blumenta } \\
\text { 1 et al., } \\
{[14]}\end{array}$ & $\begin{array}{c}\mathrm{GEH}=53 \\
\mathrm{GSE}=51 \\
\mathrm{AG}=49 \\
\mathrm{PG}=49\end{array}$ & $\begin{array}{c}\mathrm{GEH}=53 \\
\mathrm{GSE}=52 \\
\mathrm{AG}=52 \\
\mathrm{PG}=52\end{array}$ & Aerobic & 总 & 16 & 45 minutes & 3 & $\begin{array}{l}\text { Yes, } 70 \text { to } \\
85 \% \mathrm{HR} \\
\text { reserve }\end{array}$ & Yes & s DSM-IV & & $\begin{array}{l}\text { Mild to } \\
\text { moderate }\end{array}$ & Yes & $\begin{array}{c}\text { There was a significant } \\
\text { decrease in depression } \\
\text { in all groups compared } \\
\text { to baseline, with no } \\
\text { significant difference } \\
\text { between the exercise } \\
\text { and antidepressant } \\
\text { groups and between } \\
\text { groups supervised } \\
\text { exercise and exercise at } \\
\text { home. }\end{array}$ \\
\hline $\begin{array}{c}\text { Pilu et } \\
\text { al., [10] }\end{array}$ & $\begin{array}{l}E G=10 \\
\mathrm{CG}=20\end{array}$ & 50 & Strength & Yes & 32 & 60 minutes & 2 & No & Yes & $\begin{array}{l}\text { DSM-IV } \\
\text { SCID-I }\end{array}$ & $\begin{array}{c}\text { HAM-D } \\
\text { CGI/GA } \\
\text { F }\end{array}$ & - & Yes & $\begin{array}{c}\text { The group of more } \\
\text { antidepressant exercise } \\
\text { significantly improved } \\
\text { all scores during the } 8 \\
\text { months of treatment } \\
\text { compared to the control } \\
\text { group }\end{array}$ \\
\hline
\end{tabular}




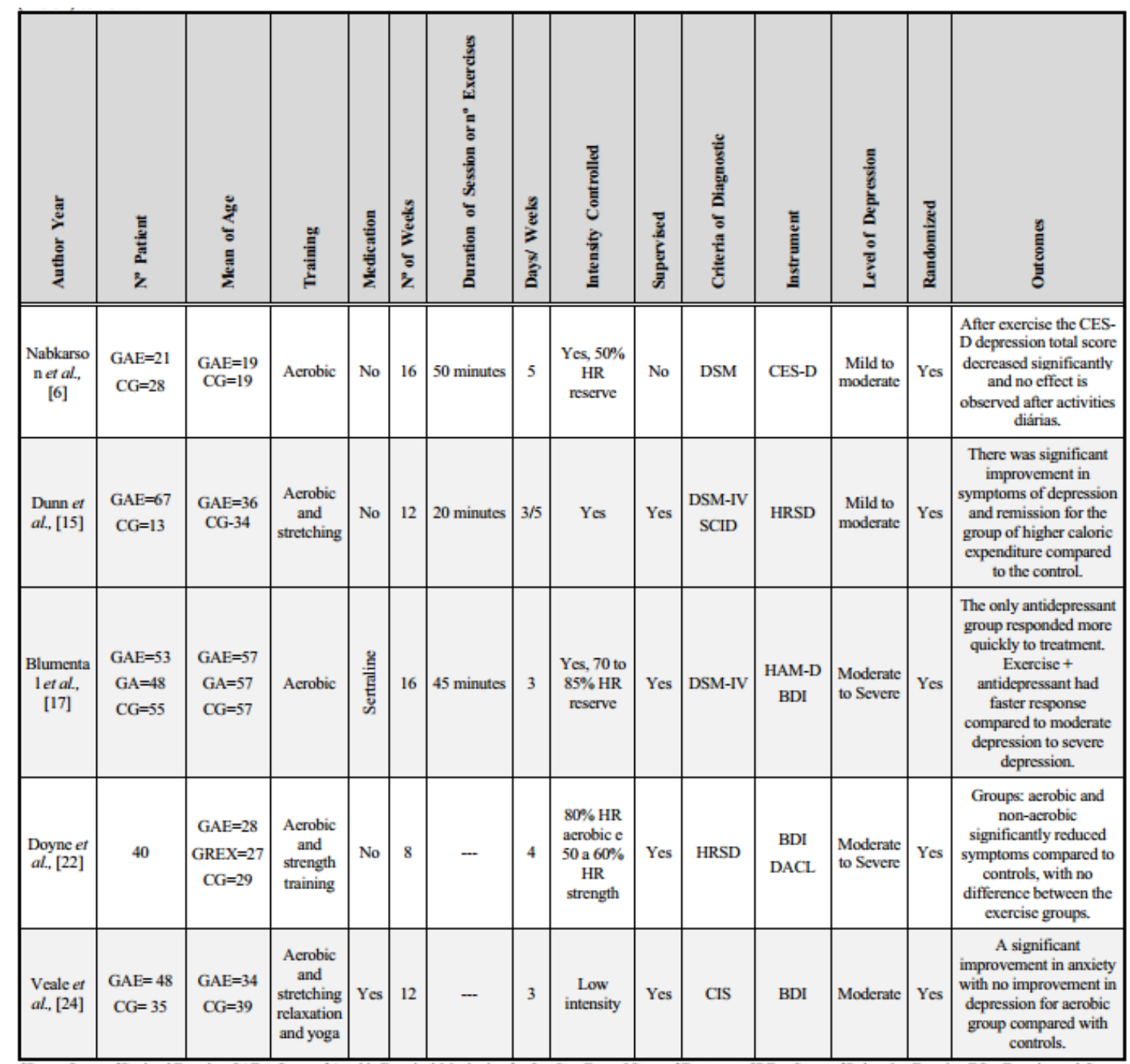

GRex - Group of Resisted Exercise, GAE - Ciroup of Aerobic Exercise* Monitoring for One Day Every 5 Days of Treatment, GRE - Group of Relaxation Exercise, EG - Experimenteal Group,
CG - Control Group, GSE - Group of Supervised Exercise, GEH- Group of Exercise at Home, AG - Group Antidepressant, PG - Placebo Group, DSM-IV - Diagnostic and Statistical Manual of Mental Disorder, CES-D - Center for Epidemiologic Studies Depression Seale, HAM-D - Hamilton Rating Scale for Depression Rate, BDI - Beck Depression Inventory, BDI-II - Beck Depression Inventory II, ESE - Exercise Self-Efficacy, DCSE - Depression Coping Self-Efficacy, CGI - Clinical Global Impression, GAF - Global Assessment of Functioning, ICD-10 International Classification for Diseases Tenth Revision, DACL - Depression Adjective Chock Lists, SCID - Structured Clinical linterview for the Diagnostic.

group and placebo group. Aerobic exercise consisted of 45 minutes, 10 heating and 5 back to calm, with intensity between 70 and $85 \%$ of HR reserve and three times a week. They found that the remission rate was similar between groups, $45 \%$ supervised exercise, $40 \%$ exercise at home and $47 \%$ antidepressant, presenting significant difference when compared $31 \%$ to the placebo group. Another very important aspect of this study was the improvement of aerobic capacity and tolerance to exercise. Differences were observed between the treatment groups with exercise, supervised exercise participants achieved higher levels of aerobic capacity after treatment $8.3 \%$, compared to the home exercise group 3.5\%. Likewise, patients in both exercise conditions showed higher tolerance to exercise compared to patients who received pills, the supervised exercise group improved $18.8 \%$ and the home exercise group improved $7.5 \%$. Whereas antidepressant group showed a decrease of $0.8 \%$ in aerobic capacity and improvement of $3.9 \%$ in exercise tolerance, and the placebo group decreased by $4 \%$ in aerobic capacity and $2.3 \%$ in exercise tolerance. As for the depression scores, a significant decrease after 16 weeks of treatment on a scale of Hamiton compared to baseline, while the supervised exercise group decreased by 7.2, exercise at home 7.1 and antidepressant and placebo groups, 6.1. There 
Table 2. Risk of bias of the papers that investigated the chronic effect of exercise in patients with depression.

\begin{tabular}{|c|c|c|c|c|c|c|}
\hline Sudy & EC & CG & RD & RS & IR & RDM \\
\hline Chalder et al., [23] & Yes & Yes & Yes & No & Yes & Yes \\
\hline Krogh et al., [21] & Yes & Yes & Yes & Yes & Yes & Yes \\
\hline Mota-Pereira et al., [11] & Yes & Yes & Yes & Yes & Yes & Yes \\
\hline Krogh et al., [20] & Yes & Yes & Yes & No & Yes & Yes \\
\hline Chu et al., [19] & Yes & Yes & Yes & No & Yes & Yes \\
\hline Hoffinan et al., [18] & Yes & Yes & Yes & Yes & Yes & Yes \\
\hline Blumental et al., [14] & Yes & Yes & Yes & Yes & Yes & Yes \\
\hline Pilu et al., [10] & Yes & Yes & Yes & Yes & Yes & Yes \\
\hline Nabkarson et al., [6] & Yes & Yes & Yes & No & Yes & Yes \\
\hline Dunn et al., [15] & Yes & Yes & Yes & Yes & Yes & Yes \\
\hline Blumental et al., [17] & Yes & Yes & Yes & No & Yes & Yes \\
\hline Doyne et al., [22] & Yes & Yes & Yes & No & Yes & Yes \\
\hline Veale et al., [24] & Yes & Yes & Yes & No & Yes & Yes \\
\hline
\end{tabular}
Measure.

was no significant difference between exercise and antidepressant groups as there were no between supervised exercise groups and exercise at home. According to the authors the data suggest that social support was not necessarily essential to the therapeutic benefit of exercise, suggesting some psychological factors to explain the effect that exercise has on depressed mood, self-efficacy, mastery, positive thoughts. The authors concluded that the efficacy of treatment with exercise seems to be similar to the treatment in patients who received antidepressants only, and both were better than placebo. Hoffman and colleagues [18] performed a survey of 202 depressed patients of both genders. This sample was randomly divided into four groups: aerobic exercise, group supervised, group exercise at home, antidepressant and placebo groups, with doses ranging from (50 to 200mg). The objective was to evaluate the effects at 16 weeks of aerobic exercise (running on a treadmill 3x/week $70-85 \%$ $\mathrm{HRR}$ ) on neurocognitive function in patients with depressive disorder. Criteria used for diagnosis and the severity of symptoms the Structured Clinical Interview for Diagnostic (SCID), Statistical Manual of Mental Disorders (DSM-IV) and the HAM-D. Tests were also used: Animal Naming, Controlled Oral Word Association Test (COWAT), Wechsler Adult Intelligence Scale Revised (WAIS-R) Digit Span subtest from the WAIS-R, Ruff 2 \& 7 Test, Stroop Color and Word Test, Trail Making Test (TMT), Wechsler Memory Scale (WMS) Logical Memory subtest and from the WMS to assess neurocognitive function. The data showed that the exercise groups showed higher (VO2 peak) and increased tolerance to exercise on treadmill compared to groups receiving pills (placebo group decreased by $4 \%$ in VO2 peak and $2 \%$ tolerance on treadmill. As regards the results of neurocognitive function, the data suggest that exercise had no clinically significant improvements in neurocognitive function in patients, and that the reduction in the severity of depressive symptoms was weakly associated with better neurocognitive performance, the eleven tests, only two were significant: Ruff total and digit symbol, and that these findings may have been found by chance. The authors found little evidence to support the benefits of an aerobic exercise intervention on neurocognitive performance in patients with depression. 
Nabkarsorn and colleagues [6] completed a randomized controlled study with 49 depressed women, mean age of 19 years. In this study the sample was divided into two groups, a group of 21 volunteers, who started with aerobic exercise for 8 weeks and then another 8 weeks with daily activities, the other group with 28 volunteers made the reverse order. Aerobic exercise (running group), during 50 minutes, 5days/week for 8 weeks with lower than 50\% HRR intensity. The scale of the Centre for Epidemiologic Studies Depression (CES-D) was applied to confirm and quantify the level of depression. The purpose of this study was to investigate the effects of physical exercise on depression, neuroendocrine stress hormones and physiological variables skills in female volunteers and adolescents with mild to moderate depressive nonclinical symptoms. The CES-D scores of the group that started with exercise significantly decreased the psychological effects after aerobic exercise. Slightly increased after daily activity, but was still significant compared to baseline values. The group started with daily activity also showed similar results after exercise and not significantly after daily activity compared to baseline. After physical training, both groups of subjects had lower HRR compared with the values after the phase of daily activity and at study start. Furthermore, the induced improvements by training in cardiopulmonary fitness were significant for both groups, as indicated by an increase in lung capacity and estimated peak oxygen uptake and a higher level of workload during the exercise test. After the phase of daily activity, none of the data significantly differed from the baseline values. Mean body weight did not change significantly throughout the experimental period. The authors suggest that the results of this study showed a relationship with the reduction in resting heart rate observed after training, indicating a decrease in the cardiovascular response to sympathetically mediated and psychophysical stress. Such neuroendocrine action has been considered a plausible mechanism to explain the effects of exercise on symptoms. Regular exercise seems to be able to offer a variety of benefits that can help promote physiological and psychological well-being in adolescent females with depressive symptoms. Chu and colleagues [19] conducted a study of 54 women with symptoms of depression, this research was done during 10 weeks, participants were randomly divided into three groups: high intensity aerobic exercise between $65 \%$ and $75 \%$ of VO2 reserve, low intensity $40 \%$ to $55 \%$ of VO2 reserve and the control group with stretching exercises. Aerobic exercise consisted of 30 to 40 minutes of treadmill, 3-4 days/week. With the objective to examine the effect of two different intensities of aerobic exercise on symptoms of depression, controlled by the total caloric expenditure. The total energy expenditure of groups of high intensity (1007.3kcal/week) and low intensity (905.2kcal/week) were significant compared to the control group ( $215.8 \mathrm{kcal} /$ week), but was not significant between groups. The BDI-II scores had decreased in all groups during treatment. Though the high intensity group (HI) had significant improvement of symptoms in relation to groups of low-intensity (LO) and control group (CG) in the 5th week (HI 9.7 vs LO 15.9 - HI 9.7 vs GC 15.9) and 10 week (HI LO 6.4 vs 12.7 - 6.4 vs HI GC 14.6). For scores of Exercise Self-Efficacy (ESE) all groups showed improvement during 10 weeks of treatment with no significant difference between them for scores of Depression Coping Self-Efficacy (DCSE), overall significant increase from $69 \%$ to $75.5 \%$ in the 10 weeks of treatment. The authors attribute these results to the fact that all participants in the exercise group were influenced by the expectation, social contact and personal attention given by researchers, generally improving depressive symptoms. The aerobic exercise of low and high intensity was associated with reductions in depression symptoms of low and moderate levels in sedentary women. Dunn and colleagues [15] conducted a study with 80 patients with depression of mild to moderate intensity for 12 weeks. This study evaluated the influence of frequency on energy expenditure and aerobic exercise decreased depression symptoms, which compared the groups: $7 \mathrm{kcal} / \mathrm{kg} /$ week in 3 to 
5 days per week, $17.5 \mathrm{kcal} / \mathrm{kg} /$ week made at 3 and 5 days per week with placebo control group and stretching exercise and relax 15 to 20 minutes 3 days per week. The scores for depression HAM-D) decreased relative to baseline in all groups, public health dose (PHD) in 47\%, low dose (LD) $30 \%$, placebo $29 \%$ control. Though there was no significant difference when comparing the LD control and placebo groups, but there was a significant difference for the largest group of weekly caloric expenditure PHD. When we compared the reduction in depression scores in the frequency of exercise, it was found that there was no significant difference between the groups, where 3 -days/week and 5-days/week reduced $39 \%$ and $38 \%$ respectively. When analyzing the effect of training on the rate of remission symptoms, it was found that the PHD group was not more effective than LD, but was significant in the control group, the LD group was not significant compared to the placebo control group. As to the frequency of exercise there was no difference between the groups of 3-days/week and 5-days/week in relation to remission symptoms. There was also no interaction between frequency and energy expenditure, thus the authors relate these results, was not the frequency of exercise, but the metabolic stress caused by the body energy expenditure, with doses according to Public Health Recommendations. Aerobic exercise in doses consistent with the Public Health Recommendations was effective in treating depression.

\section{Aerobic Versus Non-Aerobic Exercise}

Krogh and colleagues [20] conducted a research with 165 adult patients with depression between 18 and 55 years, with the objective of evaluating the benefits and damages caused by training with aerobic exercise, strength and relaxation for a period of four months with 2 sessions per week, for selection criteria and evaluation, ICD-10, HAM-D17 and BDI were used. The sample was divided into three groups: aerobic exercise group, $n=55$, group strength training exercise, $n=55$ and the relaxation group, $n=55$. The exercises were: six exercises for large muscle groups (circuit training) - (50-75\% 1RM 2-3 sets of 8 to 12 repetitions), aerobic exercise was done in 10 different ergometers with 80-minute sessions. ( 2 minutes $\times 2$ stimulus recovery 70\% MHR during the first 8 weeks) and (in the last 8 weeks 3 minute recovery stimulus $\times 189 \% \mathrm{MHR}$ ), the relaxation exercises were mild (20 to 30 minutes of relaxation with balls, 10 to 20 minutes of stretching with bats followed by 20 to 30 minutes of balance exercises). After the fourth month the data revealed a significant increase in strength gain of the group of strength exercises compared to group relaxation exercises. Similarly there was a significant difference in maximal oxygen uptake (VO2max) aerobic group when compared with the relaxation group. For depressive symptoms there were no significant difference between groups at the end of the HAM-D17 training, nor were there after the monitoring period that lasted six months, but the data support that the resistance exercise group was less absent to work in a significant way compared to relaxation group, the same was not observed when comparing the aerobic group vs stretching. The exercise has not generated improvement in depression severity, but strength training helped reduce the lack of patients to work, without improvement in cognitive ability. Krogh and colleagues [21] did this search in 115 depressed patients, 59 in group stretching exercises and 56 patients in the aerobic exercise group, both for a period of 3 months with 3 sessions per week. The aerobic group did a 45 minute cycle ergometer, 5 minutes warm low intensity, 30 minutes $65 \%$ of maximum capacity, 10 minute cool-down low intensity in the first month, and 70 and $80 \%$ for the second and third month respectively. The stretching group did the first 10 minutes of heating in a stationary bike with low intensity, followed by 20 minutes of stretching and ending with 15 minutes of several low 
intensity exercises with ball. In this study DSM-IV was used, for depressive symptoms was used HAM-D17 and BDI and anxiety symptoms were measured by HAM-F14 and BAI. Depression scores for the HAM-D post-intervention between the groups was not a significant scale. At follow-up of volunteers, participants of the aerobic exercise group showed: higher maximum oxygen uptake of $4.4 \mathrm{l} / \mathrm{kg} / \mathrm{min}$, visuo-spatial memory in the Rey Complex Figure Test and lower levels of blood glucose $0,2 \mathrm{mmol} / \mathrm{l}$ compared to the group of stretching exercises. At follow-up, four volunteers from the aerobic group and eight stretching group started treatment with an antidepressant, but this had no significant influence on the results. The results suggest that aerobic exercise for three months did not sustain any improvement in depressive symptoms, however there were great benefits such as higher VO2max, reduced waist perimeter and blood glucose. Doyne and colleagues [22] developed a study in 40 adult women with depression between 18 and 35 years old. The purpose of this study was to compare the effectiveness of aerobic exercise training and not with the control group, for a period of 8 weeks with 4 weekly sessions and see if the effect of aerobic training is a necessary condition for improvement of depressive symptoms condition. Aerobic exercise was performed on an indoor track of a mile, $4 x$ /week with an intensity of $80 \%$ of MHR, 5 to 10 minutes in both the heating and cool-down with stretching exercises. Criteria used for the opportune diagnosis was Diagnostic Research Criteria (DRC), psychological measures in HAMD, Beck Depression inventory (BDI) and the Depression Adjective Check Lists (DACL). Subjects were divided into: group aerobic exercise, resistance exercise and control groups. The BDI and HAM-D scores were analyzed using a MANOVA between groups $x$ time for the pre training, during and post training. Scheffe tests showed significant reductions in depression scores over time for groups of aerobic exercise and strength in the moments during and after training and no difference for the control group. At post treatment, during follow up, scores of aerobic and strength group were significantly lower than the control group in time 7 and 12 months with no difference between the two exercise groups, as there were no improvements in fitness, the authors attribute cognitive behavioral mechanisms as responsible for the improvement of depression, it can produce a feeling of accomplishment and increased self-efficacy as noticeable improvements in performance. These changes were consistent with cognitive and behavioral approaches that have resulted in positive results in reducing depression. Both exercise conditions significantly reduced the symptoms of depression compared to the control group. There was no significant difference between the exercise groups, these results indicated that both aerobic exercise and resistance significantly reduced depression and that these results do not depend on the coming cardiopulmonary benefits of aerobic exercise. Chalder and colleagues [23] conducted a survey to investigate the effectiveness of facilitated physical activity, as adjunctive therapy to primary care in adults with depression. We evaluated 361 subjects, consisting of two groups: intervention group $n=182$, control group $n=179$. It is important to point out that the intervention was based on the theory and aimed to provide individualized support and encourage volunteers to perform physical activity to achieve a volume of 150min per week, these incentives were performed in three classroom sessions and over 10 phone calls over 8 months. Measurements were taken at baseline; 4 months post intervention, 8 and 12 months of follow up, using the Clinical Interview Schedule-Revised and the BDI. There was no evidence that the intervention group had improved mood disorders according to BDI scores 4 months after baseline compared to the group that received only special care. Likewise was no significant difference between groups in periods of 8 and 12 months of follow up. There was no evidence that the intervention group had reduced the use of antidepressants compared to controls during screening. However, the intervention group reported greater volume of physical activity compared to controls during follow-up. The 
addition of a facilitator of the exercise to usual care did not improve symptoms of depression or reduced the use of antidepressants compared to usual care alone. Veale and colleagues [24] conducted a study in patients with refractory depression, with the objective to compare the additional aerobic exercise to conventional treatment that showed some benefit to patients. In this study he compared two groups: aerobic exercise group, three times a week for 12 weeks (the session began with a warm-up stretching exercises followed by a program running low intensity), the control group without any intervention, but both groups continued with their conventional treatments, such as antidepressants and other therapies, noting that not all members of each group were taking antidepressants, but there was no significant difference between the number of patients treated in the two groups. This study was divided into two parts, the first with sedentary individuals. After 12 weeks of treatment there was a significant difference in the Clinical Interview Scores (CIS) and anxiety traits, as well as the maximum oxygen uptake of aerobic group compared with controls, but no difference for data BDI. In the second phase of the study the aerobic exercise group with the group stretching exercise, relaxation and yoga, all with low intensity, in patients already exercised one to three times per week was compared. There was no difference in any of the measured data: as a CIS, traces of anxiety, BDI and maximum oxygen uptake. The findings of the first phase of the study show that there was no additional effect in improving symptoms of depression, but the possible mechanisms responsible for the improvement in anxiety scores and the CIS may be related to care received from health professionals during the treatment, social interaction, muscle relaxation, motivation and regular routine.

\section{Methodological Differences}

Among the selected studies examining the effects of exercise alone, Assistant to antidepressant drug or to any other alternative therapy on symptoms of depression, we found a range of different outcomes. The factors that may be related to this fact are numerous, such as: severity of symptoms of depression, duration of intervention, volume and intensity of exercise and even the fact that the exercise is aerobic or strength. Studies comparing the effect of exercise and antidepressant with antidepressant alone in patients with depression disorders $[10,11,17]$ generally found improvements in all operating parameters and depression, but with some particularities, however in moderate depression we have faster therapeutic response using exercise and antidepressant (45min $3 x$-week for 4 months) while for severe depression only using antidepressant therapeutic the response was faster [17]. Another study obtained significant results of the exercise group compared to the control (antidepressant), didn't used aerobic exercise but instead strengthening exercises, though good result may be related to the intervention period that was twice as much ( $2 \times 60 \mathrm{~min}$-week for 8 months) [10]. A study that used aerobic exercise and antidepressants as treatment in depressed in the short term [13], interestingly also found improvement in symptoms of depression, it was used a 30 minutes of intervals of high intensity running in 10 consecutive days, possibly a form of execution and intensity generating a great metabolic stress, contributing favorably, which was not done by any other long-term study. Other researches have investigated whether different exercise intensities had different therapeutic responses $[6,15,19]$. One study compared high-intensity aerobic exercise (65-75\%) versus low intensity exercise (40-55\%) of VO2 reserve with the same volume of exercise and stretching a control [19] group. Another study also investigated exercise of different intensities but made by, caloric expenditure, (7 kcal/kg/week and $17.5 \mathrm{kcal} / \mathrm{kg} /$ week) both running on 3 and 5 days a 
week and a control group of stretching [15]. In both studies [15, 19] all groups showed improvement in depressive symptoms compared to baseline, but only the groups 65 to $75 \%$ and $17.5 \mathrm{kcal} / \mathrm{kg} /$ week were significant to their respective controls and lower intensity. Of the thirteen studies were selected in this investigation, five researched whether aerobic exercise was more effective or necessary condition to reduce the symptoms of depression compared with non-aerobic exercise [20-24]. Though only one study [22] found a significant difference in reducing depressive symptoms when compared the effectiveness of aerobic exercise with the control group, but no difference for the group of non-aerobic exercise (strength), i.e. this type of exercise was also effective, demonstrating that aerobic component is not necessary for symptom improvement condition, and the fact that only this study demonstrated positive effects may be related to your exercise protocol and sample characteristics, with a mean age of 27 years were 8 weeks of aerobic exercise weekly with 4 to $80 \%$ of maximal HR sessions, and $60 \%$ of maximal HR for strength exercise. The studies that showed no significant difference or positive effects $[20,21,23,24]$ on depressive symptoms, had samples with higher age and exercise protocols with lower intensity, ranging from $50 \%$ to $89 \%$ of maximal $\mathrm{HR}$ at the end treatment and with only 2 or 3 sessions per week, another difference was that all these studies were performed with patients with mild to moderate depression, while only presented the positive [22] effects consisted of patients with depression of moderate to severe intensity, suggesting that the sample age, severity of symptoms, exercise intensity and number of days per week may have influenced the results.

\section{Neurobiological Mechanisms}

The neurobiological effects of exercise appear to influence several neural mechanisms that are related to depression $[6,14,25-41]$. Evidence suggests that physical exercise causes physiological changes on monoamine levels [42-49], changes the levels of cortisol, the stress hormone [33, 48, 49-51], causing adaptations in limbic structures that have depression implications and positive effects of neurotrophic factors [25, 27, 30-32, 40, 41, 48, 52-58]. Studies have shown that antidepressants and exercise have similar effects in the treatment of depression $[14,17]$. Regarding the levels of monoamine, studies have indicated as the primary cause of depression, dysfunction of serotonin $(5 \mathrm{HT})[59,60]$. The decreased levels of 5 hydroxyindoleacetic (5HIAA), the major metabolite of 5-HT in the human body, decrease in plasma tryptophan, low proportion of amino acid tryptophan and $5 \mathrm{HT}$ acid function abnormalities are observed in patients with depression [61,62]. Though these monoamine levels may be increased with regular and systematic practice of physical exercise. Studies have shown that significant levels of noradrenaline and 5TH, as well as the expression of 5HIAA and $5-\mathrm{HT} 2 \mathrm{C}$ receptors in the limbic system have been reported following exercise on a treadmill of chronic form [42-45, 47, 48]. Another important mechanism that suffers major adaptations is the hypothalamic-pituitary-adrenal system (HPA) subjected to chronic stress has great hyperactivity and elevated levels of glucocorticoids [63-65], which are harmful to the body. Around $50-60 \%$ of patients with depression show changes in the HPA system [68], resulting in the alteration of the regulation of adrenocorticotropin (ACTH) and cortisol secretion activity $[66,67]$. So in this sense, one of the main effects of endurance training is to alter the tissue sensitivity to glucocorticoids [51], another effect of exercise is the activation of the sympathetic nervous system that stimulate the secretion of glucocorticoids [69-72]. Studies have shown that physically active people have different cortisol responses after acute exercise are attenuated and dissipate more quickly than less active individuals $[33,49,50]$. Therefore, 
exercise can reduce symptoms of depression due to their influence on the HPA system and glucocorticoid attenuated response to stressful stimuli. factor that influences the HPA system is the peptide hormone atrial natriuretic peptide (ANP), which has been observed to inhibit the HPA [73-75] system. The physical activity also increases the plasma concentrations of ANP [76] and anxiolytic effects of exercise correlate with increased plasma concentrations of ANP [77]. It is known that depression can lead to neuronal cell loss and atrophy in limbic regions of the brain, including the amygdala, prefrontal cortex and hippocampus [78-84]. Depression can be associated to cognitive decline [85] functions in which the hippocampus plays a crucial role. Neurogenesis has been generally related to improvements in learning and memory function $[86,87]$. Neuroimaging study showed that depressed patients are more affected by the reduction in volume of the left hippocampus than nondepressed controls [88]. The depression causes a loss of hippocampal volume, particularly in the left hemisphere. Human studies have shown that a deficiency in the availability of BDNF is associated with vulnerability to depression [85]. The Increased the brain growth factor such as BDNF expression is related to the effects of exercise on brain plasticity, cognitive functioning and health $[27,58]$.

\section{CONCLUSION}

In this systematic review on the antidepressant effect of exercise on depression, we selected and used 13 randomized clinical trials, reaching a total sample of 1570 subjects. The data presented in this systematic review indicate that $69.3 \%$ of studies that investigated the antidepressant effect of exercise on depression showed significant results. On the other hand, the other $30.7 \%$ of the studies with depression improved only general physiological aspects, such as increased oxygen uptake, increased use of blood glucose and decreased body fat percentage, with no improvement on symptoms of depression. The randomized clinical trials reviewed here, could well attend to tighter control of prescription and monitoring of exercise and can thus benefit from better results on the anxiolytic effects of exercise. Regarding the methodology used in exercise protocols, we found that outcomes vary because of different experimental approaches. Volume, intensity and day per weeks, thus making it impossible to weave some feedback from practical application of this analysis: where aerobic exercise, strength, stretching and relaxation, ranging in were used.

\section{LIST OF ABBREVIATIONS}

$$
\begin{aligned}
& \text { 5HIAA = 5-Hydroxyindoleacetic } \\
& 5 \mathrm{HT}=\text { Serotonin } \\
& \mathrm{ACTH}=\text { Adrenocorticotropin } \\
& \mathrm{BDI}=\text { Beck Depression Inventory } \\
& \mathrm{BDI}=\text { Beck Depression inventory } \\
& \mathrm{BDNF}=\text { Brain-Derived Neurotrophic Factor } \\
& \mathrm{CBT}=\text { Cognitive-Behavioral Therapy }
\end{aligned}
$$


CES-D = Centre for Epidemiologic Studies Depression

$C G=$ Control Group

CGI = Clinical Global Impression

CIS = Clinical Interview Scores

COWAT = Animal Naming, Controlled Oral Word Association Test

DACL $=$ Depression Adjective Check Lists

DCSE $=$ Depression Coping Self-Efficacy

DRC = Diagnostic Research Criteria

DSM-IV = Statistical Manual of Mental Disorders

$E S E=$ Exercise Self-Efficacy

GAF $=$ Global Assessment Functioning

HAM-D = Hamilton Rating Scale for Depression

$\mathrm{HI}=$ High Intensity

HPA = Hypothalamic-Pituitary-Adrenal System

$\mathrm{HRR}=$ Heart Rate Reserve

$L D=$ Low Dose

LO = Low-Intensity

MDD = Major Depressive Disorder

MHR = Maximum Heart Rate

PHD = Public Health Dose

SCID = Structured Clinical Interview for Diagnostic

TMT = Trail Making Test

WAIS-R = Wechsler Adult Intelligence Scale Revised

WMS $=$ Wechsler Memory Scale

\section{REFERENCES}

[1] Cooney GM, Dwan K, Greig CA, et al. Exercise for depression. Cochrane Database Syst Rev 2013; 9: CD004366.

[2] Hammar $\AA$, Årdal G. Cognitive functioning in major depression-a summary. Front Human Neurosci 2009; 3: 26.

[3] Jayakody K, Gunadasa S, Hosker C. Exercise for anxiety disorders: systematic review. Br J Sports Med 2014; 48(3): 187-96. 
[4] Angevaren M, Aufdemkampe G, Verhaar HJ, et al. Physical activity and enhanced fitness to improve cognitive function in older people without known cognitive impairment. Cochrane Database Syst Rev 2008; 16(3): CD005381.

[5] Fountoulakis KN, Vieta E, Sanchez-Moreno J, et al. Treatment guidelines for bipolar disorder: a critical review. Journal of affective disorders 2005; 86(1): 1-10.

[6] Nabkasorn C, Miyai N, Sootmongkol A, et al. Effects of physical exercise on depression, neuroendocrine stress hormones and physiological fitness in adolescent females with depressive symptoms. Eur J Public Health 2006; 16(2): 179-84.

[7] Frazer CJ, Christensen H, Griffiths KM. Effectiveness of treatments for depression in older people. Med J Aust 2005; 182(12): 627-32.

[8] Gustafsson G, Lira CM, Johansson J, et al. The acute response of plasma brain-derived neurotrophic factor as a result of exercise in major depressive disorder. Psychiatry Res 2009; 169(3): 244-8.

[9] Laske C, Banschbach S, Stransky E, et al. Exercise-induced normalization of decreased BDNF serum concentration in elderly women with remitted major depression. Int J Neuropsychopharmacol 2010; 13(05): 595-602.

[10] Pilu A, Sorba M, Hardoy, MC, et al. Efficacy of physical activity in the adjunctive treatment of major depressive disorders: preliminary results. Clin Practice Epidemiol Mental Health 2007; $3(1): 8$.

[11] Mota-Pereira MJ, Silverio J, Carvalho S, et al. Moderate exercise improves depression parameters in treatment-resistant patients with major depressive disorder. J Psychiatric Res 2011; 45(8): 1005-11.

[12] Stanton R, Reaburn P. Exercise and the treatment of depression: A review of the exercise program variables. J Sci Med Sport 2014; 17: 177-82.

[13] Knubben K, Reischies FM, Adli M, et al. A randomised, controlled study on the effects of a short-term endurance training programme in patients with major depression. Br J Sports Med 2007; 41(1): 29- 33.

[14] Blumenthal JA, Babyak MA, Doraiswamy PM, et al. Exercise and pharmacotherapy in the treatment of major depressive disorder. Psychosom Med 2007; 69(7): 587-96.

[15] Dunn AL, Trivedi MH, Kampert JB, et al. Exercise treatment for depression: efficacy and dose response. Am J Prevent Med 2005; 28(1): 1-8.

[16] Moher D, Liberati A, Tetzlaff J, et al. Preferred reporting items for systematic reviews and meta-analyses: the PRISMA statement. Ann Intern Med 2009; 151(4): 264-9.

[17] Blumenthal JA, Babyak MA, Moore KA, et al. Effects of exercise training on older patients with major depression. Arch Intern Med 1999; 159(19): 2349-56.

[18] Hoffman BM, Blumenthal JA, Babyak MA, et al. Exercise fails to improve neurocognition in depressed middle-aged and older adults. Med Sci Sports Exercise 2008; 40(7): 1344.

[19] Chu I, Buckworth J, Kirby TE, et al. Effect of exercise intensity on depressive symptoms in women. Mental Health Phys Activity 2009; 2(1): 37-43. 
[20] Krogh J, Saltin B, Gluud C, et al. The DEMO trial: a randomized, parallel-group, observerblinded clinical trial of strength versus aerobic versus relaxation training for patients with mild to moderate depression. J Clin Psychiatry 2009; 70(6): 790-800.

[21] Krogh J, Videbech P, Thomsen C, et al. DEMO-II trial. Aerobic exercise versus stretching exercise in patients with major depression a randomised clinical trial. PloS One 2012; 7(10): e48316.

[22] Doyne EJ, Ossip-Klein DJ, Bowman ED, et al. Running versus weight lifting in the treatment of depression. J Consult Clin Psychol 1987; 55(5): 748.

[23] Chalder M, Wiles NJ, Campbell J, et al. Facilitated physical activity as a treatment for depressed adults: randomised controlled trial. Br Med J 2012; 344: e2758.

[24] Veale DMWC, Le Fevre K, Pantelis C, et al. Aerobic exercise in the adjunctive treatment of depression: a randomized controlled trial. J R Soc Med 1992; 85(9): 541-4.

[25] Carro E, Nuñez A, Busiguina S, et al. Circulating insulin-like growth factor I mediates effects of exercise on the brain. J Neurosci 2000; 20(8): 2926-33.

[26] Chaouloff F. Physical exercise and brain monoamines: a review. Acta Physiol Scand 1989; 137(1): 1-13.

[27] Cotman CW, Berchtold NC, Christie LA. Exercise builds brain health: key roles of growth factor cascades and inflammation. Trends Neurosci 2007; 30(9): 464-72.

[28] Dishman RK. Brain monoamines, exercise, and behavioral stress: animal models. Med Sci Sports Exerc 1997; 29(1): 63-74.

[29] Duman CH, Schlesinger L, Russell DS, et al. Voluntary exercise produces antidepressant and anxiolytic behavioral effects in mice. Brain Res 2008; 1199: 148-58.

[30] Ernst C, Olson AK, Pinel JP, et al., Antidepressant effects of exercise: evidence for an adultneurogenesis hypothesis? J Psychiatry Neurosci 2006; 31(2): 84-92.

[31] Fabel K, Tam B, Kaufer D, et al. VEGF is necessary for exerciseinduced adult hippocampal neurogenesis. Eur J Neurosci 2003; 18(10): 2803-12.

[32] Hunsberger JG, Newton SS, Bennett AH, et al. Antidepressant actions of the exerciseregulated gene VGF. Nat Med 2007; 13(12): 1476-82.

[33] Luger A, Deuster PA, Kyle SB, et al. Acute hypothalamicpituitary-adrenal responses to the stress of treadmill exercise. Physiologic adaptations to physical training. N Engl J Med 1987; 316(21): 1309-15.

[34] Ströhle A, Feller C, Onken M, et al. The acute antipanic activity of aerobic exercise. Am J Psychiatry 2005; 162(12): 2376-8.

[35] Ströhle A, Graetz B, Scheel M, et al. The acute antipanic and anxiolytic activity of aerobic exercise in patients with panic disorder and healthy control subjects. J Psychiatr Res 2009; 43(12): 1013-7.

[36] Van Praag H, Christie BR, Sejnowski TJ, et al. Running enhances neurogenesis, learning, and long-term potentiation in mice. Proc Natl Acad Sci USA 1999; 96(23): 13427-31. 
[37] Van Praag H, Kempermann G, Gage FH. Running increases cell proliferation and neurogenesis in the adult mouse dentate gyrus. Nat Neurosci 1999; 2(3): 266-70.

[38] Helmich I, Latini A, Sigwalt A, et al. Neurobiological alterations induced by exercise and their impact on depressive disorders. Pract Epidemiol Ment Health 2010; 6: 115-125.

[39] Sigwalt AR, Budde $\mathrm{H}$, Helmich I, et al. Molecular aspects involved in swimming exercise training reducing anhedonia in a rat model of depression. Neuroscience 2011; 192: 661-74.

[40] Fuss J, Ben Abdallah NMB, Vogt MA, et al. Voluntary exercise induces anxiety-like behavior in adult C57BL/6J mice correlating with hippocampal neurogenesis. Hippocampus 2010; 20(3): 364- 76.

[41] Cassilhas RC, Antunes HKM, Tufik S, et al. Mood, anxiety, and serum IGF-1 in elderly men given 24 weeks of high resistance exercise. Percept Mot Skills 2010; 110(1): 265-76.

[42] Gordon R, Spector S, Sjoerdsma A, et al. Increased synthesis of norepinephrine and epinephrine in the intact rat during exercise and exposure to cold. J Pharmacol Exp Ther 1966; 153(3): 440-7.

[43] Barchas JD, Freedman DX. Brain Amines: Response to Physiological Stress. Biochem Pharmacol 1963; 12: 1232-5.

[44] Chaouloff F, Elghozi JL, Guezennec $Y$, et al. Effects of conditioned running on plasma, liver and brain tryptophan and on brain 5-hydroxytryptamine metabolism of the rat. Br J Pharmacol 1985; 86(1): 33-41.

[45] Acworth I, Nicholass J, Morgan B, et al. Effect of sustained exercise on concentrations of plasma aromatic and branched-chain amino acids and brain amines. Biochem Biophys Res Commun 1986; 137(1): 149-53.

[46] Chaouloff F, Laude D, Guezennec $Y$, et al. Motor activity increases tryptophan, 5hydroxyindoleacetic acid, and homovanillic acid in ventricular cerebrospinal fluid of the conscious rat. J Neurochem 1986; 46(4): 1313-6.

[47] Greenwood BN, Strong PV, Loughridge AB, et al. 5-HT2C receptors in the basolateral amygdala and dorsal striatum are a novel target for the anxiolytic and antidepressant effects of exercise. PLoS One 2012; 7(9): e46118.

[48] Maniam J, Morris MJ. Voluntary exercise and palatable high-fat diet both improve behavioural profile and stress responses in male rats exposed to early life stress: role of hippocampus. Psychoneuroendocrinology 2010; 35(10): 1553-64.

[49] Rudolph DL, McAuley E. Cortisol and affective responses to exercise. J Sports Sci 1998; 16(2): 121-8.

[50] Mathur DN, Toriola AL, Dada OA. Serum cortisol and testosterone levels in conditioned male distance runners and nonathletes after maximal exercise. J Sports Med Phys Fitness 1986; 26(3): 245-50.

[51] Duclos M, Gouarne C, Bonnemaison D. Acute and chronic effects of exercise on tissue sensitivity to glucocorticoids. J Appl Physiol 2003; 94(3): 869-75.

[52] Asano M, Kaneoka K, Nomura T, et al. Increase in serum vascular endothelial growth factor levels during altitude training. Acta Physiol Scand 1998; 162(4): 455-9. 
[53] Dishman RK, Renner KJ, White-Welkley JE, et al. Treadmill exercise training augments brain norepinephrine response to familiar and novel stress. Brain Res Bull 2000; 52(5): 337-42.

[54] Nibuya M, Morinobu S, Duman RS. Regulation of BDNF and trkB mRNA in rat brain by chronic electroconvulsive seizure and antidepressant drug treatments. J Neurosci 1995; 15(11): 7539-47.

[55] Vaynman SS, Ying Z, Yin D, et al. Exercise differentially regulates synaptic proteins associated to the function of BDNF. Brain Res 2006; 1070(1): 124-30.

[56] Boehme F, Gil-Mohapel J, Cox A, et al. Voluntary exercise induces adult hippocampal neurogenesis and BDNF expression in a rodent model of fetal alcohol spectrum disorders. Eur J Neurosci 2011; 33(10): 1799-811.

[57] Gomes da Silva S, Unsain N, Mascó DH, et al. Early exercise promotes positive hippocampal plasticity and improves spatial memory in the adult life of rats. Hippocampus 2012; 22(2): 347-58.

[58] Marais L, Stein DJ, Daniels WM. Exercise increases BDNF levels in the striatum and decreases depressive-like behavior in chronically stressed rats. Metab. Brain Dis 2009; 24(4): 587-97.

[59] Kari HP, Davidson PP, Kohl HH, et al. Effects of ketamine on brain monoamine levels in rats. Res Commun Chem Pathol Pharmacol 1978; 20(3): 475-88.

[60] Romanowski W, Grabiec $\mathrm{S}$. The role of serotonin in the mechanism of central fatigue. Acta Physiol Pol 1974; 25(2): 127-34.

[61] Coccaro EF, Siever LJ, Klar HM, et al. Serotonergic studies in patients with affective and personality disorders. Correlates with suicidal and impulsive aggressive behavior. Arch Gen Psychiatry 1989; 46(7): 587-99.

[62] Meltzer H. Serotonergic dysfunction in depression. Br. J Psychiatry Suppl 1989; 8: 25-31.

[63] Lupien SJ, Buss C, Schramek TE, et al. Hormetic influence of glucocorticoids on human memory. Nonlinearity Biol Toxicol Med 2005; 3(1): 23-56.

[64] Pruessner JC, Hellhammer DH, Kirschbaum C. Burnout, perceived stress, and cortisol responses to awakening. Psychosom Med 1999; 61(2): 197-204.

[65] Holsboer F. The corticosteroid receptor hypothesis of depression. Neuropsychopharmacol 2000; 23(5): 477-501.

[66] Parker KJ, Schatzberg AF, Lyons DM. Neuroendocrine aspects of hypercortisolism in major depression. Horm Behav 2003; 43(1): 60-6.

[67] Ströhle A. Die Neuroendokrinologie von Stress und die Pathophysiologie und Therapie von Depression und Angst [The neuroendocrinology of stress and the pathophysiology and therapy of depression and anxiety]. Nervenarzt 2003; 74(3): 279-91.

[68] Droste SK, Chandramohan Y, Hill LE, et al. Voluntary exercise impacts on the rat hypothalamic-pituitary-adrenocortical axis mainly at the adrenal level. Neuroendocrinology 2007; 86(1): 26- 37. 
[69] Droste SK, Gesing A, Ulbricht S, et al. Effects of long-term voluntary exercise on the mouse hypothalamic-pituitaryadrenocortical axis. Endocrinology 2003; 144(7): 3012-23.

[70] Budde H, Pietrassyk-Kendziorra S, Bohm S, et al. Hormonal responses to physical and cognitive stress in a school setting. Neurosci Lett 2010; 474(3): 131-134.

[71] Budde H, Voelcker-Rehage C, Pietrassyk-Kendziorra S, et al. Steroid hormones in the saliva of adolescents after different exercise intensities and their influence on working memory in a school setting. Psychoneuroendocrinology 2010; 35(3): 382-91.

[72] Kellner M, Wiedemann K, Holsboer F. Atrial natriuretic factor inhibits the $\mathrm{CRH}$-stimulated secretion of ACTH and cortisol in man. Life Sci 1992; 50(24): 1835-42.

[73] Kellner M, Herzog L, Holsboer F, et al. Circadian changes in the sensitivity of the corticotropin-releasing hormones-stimulated HPA system after arginine vasopressin and atrial natriuretic hormone in human male controls. Psychoneuroendocrinology 1995; 20(5): 515- 24.

[74] Ströhle A, Kellner M, Holsboer F, et al. Atrial natriuretic hormone decreases endocrine response to a combined dexamethasonecorticotropin-releasing hormone test. Biol Psychiatry 1998; 43(5): 371-5.

[75] Mandroukas K, Zakas A, Aggelopoulou N, et al. Atrial natriuretic factor responses to submaximal and maximal exercise. Br J Sports Med 1995; 29(4): 248-51.

[76] Ströhle A, Feller C, J Strasburger C, et al. Anxiety modulation by the heart? Aerobic exercise and atrial natriuretic peptide. Psychoneuroendocrinology 2006; 31(9): 1127-30.

[77] Videbech P, Ravnkilde B. Hippocampal volume and depression: a meta-analysis of MRI studies. Am J Psychiatry 2004; 161(11): 1957-66.

[78] Malykhin NV, Carter R, Seres P, et al. Structural changes in the hippocampus in major depressive disorder: contributions of disease and treatment. J Psychiatry Neurosci 2010; 35(5): $337-43$.

[79] McEwen BS. Physiology and neurobiology of stress and adaptation: central role of the brain. Physiol Rev 2007; 87(3): 873- 904.

[80] Duman RS, Li N. A neurotrophic hypothesis of depression: role of synaptogenesis in the actions of NMDA receptor antagonists. Philos Trans R Soc Lond B Biol Sci 2012; 367(1601): 2475-84.

[81] Barbany G, Persson H. Regulation of Neurotrophin mRNA Expression in the Rat Brain by Glucocorticoids. Eur J Neurosci 1992; 4(5): 396-403.

[82] Duman RS, Monteggia LM. A neurotrophic model for stressrelated mood disorders. Biol Psychiatry 2006; 59(12): 1116-27.

[83] Greenwood BN, Spence KG, Crevling DM, et al. Exercise-induced stress resistance is independent of exercise controllability and the medial prefrontal cortex. Eur J Neurosci 2013; 37(3): 469-78.

[84] Neves-Pereira M, Mundo E, Muglia P, et al. The brain-derived neurotrophic factor gene confers susceptibility to bipolar disorder: evidence from a family-based association study. Am J Hum Genet 2002; 71(3): 651-5. 
[85] Leuner B, Gould E, Shors TJ. Is there a link between adult neurogenesis and learning? Hippocampus 2006; 16(3): 216-24.

[86] Winocur G, Wojtowicz JM, Sekeres M, et al. Inhibition of neurogenesis interferes with hippocampus-dependent memory function. Hippocampus 2006; 16(3): 296-304.

[87] Bremner JD, Narayan $M$, Anderson ER, et al. Hippocampal volume reduction in major depression. Am J Psychiatry 2000; 157(1): 115-8.

[88] Salehi I, Hosseini SM, Haghighi M, et al. Electroconvulsive therapy and aerobic exercise training increased BDNF and ameliorated depressive symptoms in patients suffering from treatment-resistant major depressive disorder. J Psychiatr Res 2014; 57: 117-24. 